\title{
Half-lives of self-purification for various isotopes in soils of the Chernobyl Exclusion Zone
}

\author{
M. Bondarkov ${ }^{1}$, Yu. Ivanov ${ }^{1}$, D. Bondarkov ${ }^{1}$, S. Gaschak ${ }^{1}$, A. Maksimenko ${ }^{1}$, \\ R.K. Chesser ${ }^{2}$, B. Rodgers ${ }^{2}$ and M. Zheltonozhskaya ${ }^{3}$ \\ ${ }^{1}$ Chornobyl Center for Nuclear Safety, Radioactive Waste and Radioecology, International \\ Radioecology Laboratory, Slavutych 07100, Ukraine \\ ${ }^{2}$ Texas Tech University, Lubbock, TX 79409-3131, USA \\ ${ }^{3}$ Institute for Nuclear Research, 03680 Kiev, Ukraine
}

\begin{abstract}
During 2001-2002 we investigated current contamination of soils in several places in the Chornobyl zone. We have measured the content of alpha emitting isotopes $\mathrm{Pu},{ }^{241} \mathrm{Am},{ }^{154,155} \mathrm{Eu},{ }^{90} \mathrm{Sr}$, and ${ }^{137} \mathrm{Cs}$ in layers of soil up to the depth of $30 \mathrm{~cm}$. By including the two mechanisms of migration: convection and diffusion in our model, we were able to estimate the ecological and effective half-lives of self-purification processes for these layers of soil. Effective half-lives vary from 20 to 400 years dependent upon the type of soil and the isotopes.
\end{abstract}

\section{INTRODUCTION}

Understanding the rates of migration and dissipation of radioisotopes in the environment is essential for predicting the effectiveness of natural remediation processes, or "self-purification". The rate of radionuclide migration in the different soil types can differ markedly. As a result, the ecological half-life $\left(\mathrm{T}_{1 / 2, \text { ecol }}\right)$ of self-purification processes for upper layers of soil may exceed, or be considerably shorter than, the physical half-life $\left(\mathrm{T}_{1 / 2}\right)$ of the radionuclide. The effective half-life $\left(\mathrm{T}_{1 / 2, \text { eff }}\right)$ is a measure of self-purification and includes both ecological and physical losses in accordance with the formula: $1 / \mathrm{T}_{1 / 2 \text {,eff }}=1 / \mathrm{T}_{1 / 2, \text { ecol }}+1 / \mathrm{T}_{1 / 2}$. We have evaluated the effective half-lives for $\mathrm{Pu},{ }^{241} \mathrm{Am}$, ${ }^{154,155} \mathrm{Eu},{ }^{90} \mathrm{Sr}$, and ${ }^{137} \mathrm{Cs}$ using measurements of contaminated soil profiles from research sites in the Red Forest and Glyboky Lake inside the Chornobyl Exclusion Zone.

\section{MATERIALS AND METHODS}

Altogether, we have measured 60 profiles from different soil types. Each soil sample was taken to a depth of $30 \mathrm{~cm}$ and separated into 8 sections. Measurements of each isotope, including ${ }^{90} \mathrm{Sr}$ [1] and alpha emitting isotopes of $\mathrm{Pu}$ [2], were carried out by spectrometric methods following previously published methods. Methods of measuring soil samples contaminated with ${ }^{90} \mathrm{Sr}$ were based on measurements of sample beta spectra using a spectrometer with a thin detector and following the fit of experimental spectra by established calibrated spectra. Measurements of alpha emitting isotopes of Pu were carried out by means of determination on uranium characteristic $\mathrm{L}_{\mathrm{x}}$-radiation following alpha decay of $\mathrm{Pu}$. Other isotopes were measured by standard gamma-spectrometers from Canberra or Ortec, with detectors represented in Table 1.

Article published by EDP Sciences and available at http://www.radioprotection.org or http://dx.doi.org/10.1051/radiopro/20095162 
Table 1. Detectors used in survey process.

\begin{tabular}{|l|c|c|c|c|c|c|c|c|}
\hline Detector & \multicolumn{2}{|c|}{$\mathrm{Si}(\mathrm{Li})$} & \multicolumn{2}{c|}{$\mathrm{Ge}$} & \multicolumn{2}{c|}{$\mathrm{Ge}^{*}$} & \multicolumn{2}{c|}{$\mathrm{Ge}^{* *}$} \\
\hline Efficiency, \% & \multicolumn{2}{|c|}{} & \multicolumn{2}{c|}{15} & \multicolumn{2}{c|}{40} & \multicolumn{2}{c|}{$1 \mathrm{~cm}^{3}$} \\
\hline \multirow{4}{*}{ Energy (E)/resolution $(\Delta \mathrm{E}), \mathrm{KeV}$} & $\mathrm{E}$ & $\Delta \mathrm{E}$ & $\mathrm{E}$ & $\Delta \mathrm{E}$ & $\mathrm{E}$ & $\Delta \mathrm{E}$ & $\mathrm{E}$ & $\Delta \mathrm{E}$ \\
\cline { 2 - 10 } & 6.4 & 0.15 & 59.5 & 0.45 & 59.5 & 0.82 & 6.4 & 0.18 \\
\cline { 2 - 10 } & 13.8 & 0.19 & 198.0 & 0.69 & 208.0 & 0.99 & 130 & 0.22 \\
\cline { 2 - 9 } & 59.5 & 0.40 & 307 & 0.82 & 661.6 & 1.33 & 59.5 & 0.36 \\
\hline
\end{tabular}

*With suppression of Compton background.

${ }^{* *}$ Small volume detector, volume is used as characterization.

Experimental bathymetrical distributions of activities were fit using a model including two mechanisms of migration: convection and diffusion [3]. The distribution is described in the following equation:

$$
\frac{\partial C(x, t)}{\partial t}=\frac{\partial}{\partial x}\left[D(x, t) \cdot \frac{\partial C(x, t)}{\partial t}\right]-V(x, t) \cdot \frac{\partial C(x, t)}{\partial t}-\lambda \cdot C(x, t)+F(x, t)
$$

where:

$\mathrm{C}(\mathrm{x}, \mathrm{t})$ - average of all of the phases of each radionuclide concentration in the soil;

$\mathrm{D}(\mathrm{x}, \mathrm{t})$ - diffusion coefficient;

$\mathrm{V}(\mathrm{x}, \mathrm{t})$ - linear velocity of radionuclide movement dependent upon soil moisture;

$\mathrm{F}(\mathrm{x}, \mathrm{t})$ - function taking into account other processes influencing migration.

The solution of the preceding equation was used to fit our experimental results. The ratio of these two mechanisms and their parameters varied in accordance to soil type and parameter values yielding fits of theoretical and empirical results. In turn, the resultant effective half-lives of radionuclides varied as a consequence of the best fit soil parameters.

\section{RESULTS AND CONCLUSIONS}

We used the convective-diffusion model parameters to evaluate the vertical transfer of radionuclides in soil. The differing contribution of radionuclide diffusion and convective transfer to total migration is shown in different landscapes and geochemical conditions.

Based on the data received concerning convectional and diffusion transfer, we have calculated values for the ${ }^{90} \mathrm{Sr},{ }^{137} \mathrm{Cs},{ }^{154} \mathrm{Eu},{ }^{241} \mathrm{Am}$ and $\mathrm{Pu}$ isotope ecological self-purification half-lives in the $5 \mathrm{~cm}$ root layer (See Table 2).

In general, it could be concluded that the migratory mobility of trans uranium nuclides and Eu isotopes is close, though some increase in Eu and Am isotope mobility as compared to Pu isotopes is observed within certain areas due to convective transfer.

The experimentally-based assessment, along with those previously published, indicate that the migratory mobility of radiologically important radionuclides released in fuel traces resulting from the ChNPP fallout is significantly lower in soils of the nearest fallout zone as compared to soils distant from the release point within the territory. The contamination in areas distant from the release point is characterized predominantly by condensation component in the fallout, and the fuel component is represented by considerably smaller fuel particulates.

The possibility of making predictive assessments of redistribution of radionuclides in the soil body is of practical importance. Being able to predict radionuclide content in the root layer of soil resulting from both natural and cultivated plant associations enables assessment of their mobility variation in migration chains within the components of these systems. Additionally, more accurate long-term values of exposure dose rate variation in radiation produced in the environment by gamma emitting radionuclides may be generated. 
Table 2. Ecological self-purification half-lives of $5 \mathrm{~cm}$ soils root layers, years.

\begin{tabular}{|l|c|c|c|c|c|}
\hline \multicolumn{1}{|c|}{ Area } & ${ }^{137} \mathrm{Cs}$ & ${ }^{90} \mathrm{Sr}$ & ${ }^{154} \mathrm{Eu}$ & ${ }^{241} \mathrm{Am}$ & $\mathrm{Pu}$ \\
\hline $\begin{array}{l}\text { Swamp land and wetland areas of the "Red } \\
\text { Forest" polygon }\end{array}$ & $28 \pm 14$ & $21 \pm 15$ & $26 \pm 11$ & $25 \pm 10$ & $100 \pm 45$ \\
\hline $\begin{array}{l}\text { Dumped areas of the "Red Forest" polygon, } \\
\text { represented by amorphous soils }\end{array}$ & $58 \pm 31$ & $46 \pm 34$ & $42 \pm 25$ & $42 \pm 22$ & $110 \pm 60$ \\
\hline $\begin{array}{l}\text { Areas of the "Red Forest" polygon, } \\
\text { represented by amorphous soils }\end{array}$ & $100 \pm 40$ & $110 \pm 55$ & $130 \pm 190$ & $230 \pm 230$ & $140 \pm 80$ \\
\hline $\begin{array}{l}\text { Areas of the "Red Forest" polygon, } \\
\text { represented by loam amorphous soils }\end{array}$ & $300 \pm 110$ & $230 \pm 130$ & $460 \pm 270$ & $460 \pm 220$ & $260 \pm 120$ \\
\hline $\begin{array}{l}\text { Areas of the nearest waterside of the Lake } \\
\text { Glyboke, represented by loamy sand (1-5 m) }\end{array}$ & $25 \pm 6$ & $83 \pm 104$ & $32 \pm 20$ & $56 \pm 52$ & \\
\hline $\begin{array}{l}\text { Areas of middle waterside of the Lake } \\
\text { Glyboke, represented by loamy sand, } \\
\text { enriched by organic substance (3-9 m) }\end{array}$ & $65 \pm 19$ & $82 \pm 96$ & $120 \pm 120$ & $72 \pm 58$ & \\
\hline $\begin{array}{l}\text { Loamy sand areas of far waterside of the } \\
\text { Lake Glyboke (3-9 m) }\end{array}$ & $180 \pm 160$ & $160 \pm 90$ & $180 \pm 130$ & $240 \pm 190$ & \\
\hline \multicolumn{1}{|c|}{ Anomalous areas } & & & & \\
\hline $\begin{array}{l}\text { Area in the far waterside of the Lake Glyboke } \\
\text { characterized by insignificant values for } \\
\text { self-purification half-lives }\end{array}$ & $29 \pm 2$ & $130 \pm 125$ & $26 \pm 5$ & $26 \pm 4$ & \\
\hline $\begin{array}{l}\text { Area within the waterside of Lake Glyboke } \\
\text { characterized by high values for } \\
\text { self-purification half-lives }\end{array}$ & $140 \pm 50$ & $39 \pm 23$ & $490 \pm 85$ & $650 \pm 180$ & \\
\hline
\end{tabular}

As per results of the survey, vertical migration of ChNPP release radionuclides in soils in the vicinity of the ChNPP proceeds at an insignificant pace. Considerably less intensive vertical migration of transuranium radionuclides as compared to ${ }^{137} \mathrm{Cs}$ and ${ }^{90} \mathrm{Sr}$ was observed. Deposition of transuranium radionuclides in the top layer of soil will be observed during the next hundred thousand years with consideration for their vertical migration parameters and self-purification half-lives.

The survey results reflected in the paper essentially complete, as well as expand, the existing pattern of radioecological evolution in the vicinity of the ChNPP arising during the late stages of the accident. Data on the intensity of radionuclide redistribution in soils close to the ChNPP are critical for making accurate assessments of the advisability and acceptability of rehabilitation for outlying territories. Knowledge of radioecological conditions can be used to select and assess scenarios of potential rehabilitative processes, i.e. preservation and rehabilitation of the environment, to create conditions that ensure the safety of both human lives and natural ecosystems in the event of a serious nuclear accident.

\section{References}

[1] Bondarkov, M.D., Bondarkov D.M. and Zhelonozhsky, V.A. et al. The method of ${ }^{90} \mathrm{Sr}$ concentration measurement in biological objects and soil samples without radiochemistry. Scientific papers of the Institute for Nuclear research 8 (2002) 162-167.

[2] Bondarkov, M.D., Zheltonozhska, M.V., Maksimenko, A.M. et al. Determination of Plutonium isotopes in Chernobyl samples by characteristic Lx-radiation of Uranium. Problems of nuclear power plants' safety and of Chornobyl, 2 (2005) 108-112.

[3] Ivanov, Yu.A., Kashparov, V.A., Khomutinin, Yu.V. et al. Vertical transfer of radionuclides of ChNPP in soils. 3. Mathematical modelling of radionuclides vertical transfer in soil profile. Radiochemistry 38 (1996) 278-284. 
